JIIA, VOLUME 8 No 2, MEI 2020

\title{
PENDAPATAN DAN EFISIENSI TEKNIS USAHATANI KUBIS DI KECAMATAN SUMBEREJO KABUPATEN TANGGAMUS
}

(Income and Technical Efficiency of Cabbage Farming in Sumberejo Tanggamus Regency)

Titis Aditya Handayani, Fembriarti Erry Prasmatiwi, Adia Nugraha

Jurusan Agribisnis, Fakultas Pertanian, Universitas Lampung,Jl.Prof.Dr.Soemantri Brojonegoro No. 1, Bandar Lampung, 35145.e-mail: fembriarti.erry@fp.unila.ac.id

\begin{abstract}
This study is to compare the income and technical efficiency of cabbage farming grown in wet land and in rainfed land and to analyse factors influencing the efficiency. The survey was conducted in Sumberejo subdistrict of Tanggamus Regency, the center of cabbage production, in January 2019. Respondents wererandomly taken 30farmers who grew cabbagein wet land and 31 who grew cabbage in rainfed land. Data are analyzed quantitatively using income, frontier, andmultiple regression analyses. The results showed that the income of cabbage farming grown in wet land and in rainfed landis different, but they both profitable. There is no difference in the technical efficiency. Factors that influence technical efficiency of cabbage farming grown in wet land and in rainfed land are farming cost (negatively) and farmers' education level and experience (possitively). The only factor influencing technical efficiency of cabbage farming grown in rainfed land is land size.
\end{abstract}

Key words: cabbage farming, income, technical efficiency

\section{PENDAHULUAN}

Indonesia merupakan negara agraris, dimana sektor pertanian menjadi basis dalam kegiatan perekonomian negara. Menurut Badan Pusat Statistik (BPS), sumber pertumbuhan ekonomi Indonesia triwulan III-2018 yang berasal dari lapangan usaha sektor pertanian sebesar 0,49 persen. Sektor pertanian juga memberikan kontribusi positif terhadap Produk Domestik Bruto (PDB) nasional sebesar Rp501,9 trilliun (BPS 2018).

Hortikultura saat ini menjadi subsektor yang menguntungkan karena pertumbuhan ekonomi yang meningkat turut memicu peningkatan konsumsi hortikultura.Berdasarkan data dari BPS (2017), PDB subsektor hortikultura atas dasar harga yang berlaku pada tahun 2017 mencapai Rp196,132 milyar, meningkat dengan laju pertumbuhan sebesar 4,66 persen.

Menurut Badan Pengkajian dan Pengembangan Perdagangan (BPPP), produk hortikultura dengan nilai ekspor terbesar pada Semester-I 2016 adalah kubis dengan pangsa mencapai 35,2 persen. Selama periode Januari-Juni 2016 nilai ekspor kubis naik rata-rata 19,1 persen per bulan. Negara Malaysia merupakan negara tujuan pertama untuk ekspor kubis dan lemon. Negara Taiwan juga menjadi negara tujuan ekspor hortikultura terbesar kedua dari sisi volume, pada Semester-I 2016 pangsanya mencapai 33,20 persen. Kubis dan kohlrabi merupakan produk ekspor hortikultura utama ke Taiwan (BPPP 2017).

Salah satu provinsi penghasil kubis di Indonesia yaitu Provinsi Lampung, dengan produktivitas sebesar 19,82 ton/ha (BPS 2018).Di Provinsi Lampung salah satu Kabupaten yang mengusahakan komoditas kubis adalah Kabupaten Tanggamus. Menurut BPS Provinsi Lampung (2018), produksi kubis Kabupaten Tanggamus adalah 769 ton dengan luas panen 58 hektare. Kabupaten Tanggamus memiliki temperatur udara rata-rata yaitu $28^{\circ} \mathrm{C}$ dan sebagian wilayahnya terletak di sekitar 500 sampai 2.000 mdplyang berada di bawah kaki Gunung Tanggamus. Curah hujan di Kabupaten Tanggamus cukup tinggi yaitu mendekatai $3.000 \mathrm{~mm}$ per tahun. Curah hujan yang cukup tinggi ini menjadikan Kabupaten Tanggamus sebagai daerah yang potensial untuk membudidayakan tanaman sayuran-sayuran salah satunya adalah komoditas kubis, namun produktivitas yang dihasilkanoleh petani belum maksimal. 
Kecamatan Sumberejo merupakan sentra produksi kubis di Kabupaten Tanggamus dengan produksi665,20 ton dan luas panen 35 hektare, sehingga produktivitasnya 19 ton/ha. Menurut BPS (2016), produktivitas kubis tertinggi di Pulau Sumatera berada di Provinsi Bengkulu sebesar 34,85 ton/ha.Apabila dibandingkan dengan Provinsi Bengkulu yang secara geografisnya hampir sama, produktivitasdi Kecamatan Sumberejo belum maksimal. Rendahnya produktivitas di Kecamatan Sumberejo karenaadanya serangan hama penyakit dan alokasi faktor produksi belum optimal, sehingga usahatani yang diusahakan belum efisien.

Menurut Balai Penyuluhan Pertanian, Perikanan, dan Kehutanan (BP3K) Kecamatan Sumberejo (2016), usahatani kubis di Kecamatan Sumberejo dibudidayakan pada lahan basah (sawah) seluas 554,5 hektare dan lahan kering (tegalan) seluas 455,8 hektare. Kondisi lahan yang berbeda ini berpengaruh terhadap produksi yang dihasilkan. Dengan demikian, perlu dianalisis apakah terdapat perbedaan antara usahatani kubis lahan sawah dan tegalan.Berdasarkan permasalahan di atas, maka penelitian ini bertujuan untuk menganalisis pendapatan, tingkat efisiensi teknis, dan faktorfaktor yang mempengaruhi efisiensi teknis usahatani kubis lahan sawah dan tegalan di Kecamatan Sumberejo, Kabupaten Tanggamus.

\section{METODE PENELITIAN}

Metode yang digunakan dalam penelitian ini adalah metode survei. Penelitian ini dilakukan di Kecamatan Sumberejo Kabupaten Tanggamus, Provinsi Lampung. Pemilihan lokasi penelitian ini dilakukan secara sengaja (purposive) dengan pertimbangan bahwa menurut BPS Kabupaten Tanggamus (2018), Kecamatan Sumberejo merupakan sentra produksi kubis di Kabupaten Tanggamus.Menurut BP3K Kecamatan Sumberejo, terdapat dua pekon yang menjadi sentra produksi kubis yaitu Pekon Simpang Kanan dan Pekon Dadapan.

Populasi petani di Pekon Simpang Kanan dan Pekon Dadapan adalah 238 dan 250 petani. Penentuan jumlah sampel menggunakan metode simple random sampling menurut Issac dan Michael (1981), sehingga diperoleh jumlah sampel di Pekon Simpang Kanan sebanyak 30 petani dan di Pekon Dadapan sebanyak 31 petani. Dengan demikian, jumlah sampel dalam penelitian ini sebanyak 61 petani. Waktu pengumpulan data dalam penelitian ini dilaksanakan pada Januari
2019. Data yang digunakan dalam penelitian ini adalah data primer dan sekunder. Data primer diperoleh dari petani dengan wawancara. Data sekunder diperoleh dari lembaga atau instansi yang berhubungan dengan penelitian. Metode analisis data yang digunakan dalam penelitian ini adalah:

\section{Analisis Pendapatan Usahatani Kubis}

Menurut Soekartawi (2002), pendapatan usahatani adalah selisih antara penerimaan atau total revenue (TR) dan semua biaya atau total cost (TC). Pendapatan usahatani dapat dihitung dengan rumus berikut:

$\pi=\mathrm{TR}-\mathrm{TC}$

Keterangan:

$\pi \quad=$ Pendapatan $(\mathrm{Rp})$

$\mathrm{TR}=$ Total Revenue $(\mathrm{Rp})$

$\mathrm{TC}=$ Total Cost $(\mathrm{Rp})$

Soekartawi (2002), menyatakan bahwa untuk mengetahui kelayakan suatu usahatani dapat dihitung dengan menggunakan analisis Revenue Cost Ratio (R/C). R/C dikenal dengan perbandingan (nisbah) antara penerimaan (TR) dan biaya (TC) dengan menggunakan rumus berikut.

$\mathrm{R} / \mathrm{C}=\frac{\mathrm{TR}}{\mathrm{TC}}$.

Dengan kriteria:

a. $\mathrm{R} / \mathrm{C}>1$, maka usahatani menguntungkan.

b. $\mathrm{R} / \mathrm{C}<1$, maka usahatani merugikan.

c. $\mathrm{R} / \mathrm{C}=1$, maka usahatani berada pada titik impas.

\section{Analisis Efisiensi Teknis Usahatani Kubis}

Analisis efisiensi teknis usahatani kubis di Kecamatan Sumberejo Kabupaten Tanggamus menggunakan fungsi produksi frontier. Pendugaan fungsi produksi frontier menggunakan linear programing sebagai berikut.

$$
\begin{array}{ll}
\text { Minimalkan } & : \text { bo }+\sum_{j} b_{j} X_{j} \ldots \ldots \ldots \ldots \ldots \ldots . .(3) \\
\text { Dengan syarat } & : \text { bo }+\sum_{j} b_{1 j} X_{j} \geq Q 1 \\
& b o+\sum_{j} b_{n j} X_{j} \geq Q n \ldots \ldots \ldots \ldots .(4)
\end{array}
$$

Seluruh variabel ditranformasikan ke dalam bentuk logaritma. Produksi frontier diperoleh dengan cara memasukkan penggunaan input ke dalam fungsi produksi frontier.

$\mathrm{bo}+\sum_{\mathrm{j}=1}^{9} \mathrm{~b}_{\mathrm{i}} \mathrm{X}_{\mathrm{j}} \geq \mathrm{Qi}$. 
Keterangan:

Qi $=$ Produksi aktual usahatani kubis ke-i ( $\mathrm{i}=$ $1,2,3, .$.

$\mathrm{Xi}=$ Sarana produksi yang digunakan

$\mathrm{X} 1=$ Benih $(\mathrm{g})$

$\mathrm{X} 2=$ Luas lahan (ha)

$\mathrm{X} 3$ = Pupuk kandang $(\mathrm{kg})$

$\mathrm{X} 4=$ Pupuk urea $(\mathrm{kg})$

$\mathrm{X} 5=$ Pupuk ZA $(\mathrm{kg})$

$\mathrm{X} 6=$ Pupuk TSP $(\mathrm{kg})$

$\mathrm{X} 7 \quad=$ Pupuk phonska $(\mathrm{kg})$

$\mathrm{X} 8=$ Pupuk NPK basf $(\mathrm{kg})$

$\mathrm{X} 9=$ Tenaga kerja (HOK)

$\mathrm{b}_{0}, \mathrm{~b}_{1}=$ Parameter penduga

Fungsi frontier diperoleh dengan cara memasukkan penggunaan faktor produksi ke dalam fungsi frontier (Soekartawi 2002).

$\mathrm{Qf}=\mathrm{bo}+\prod_{\mathrm{j}=1}^{9} \mathrm{~b}_{\mathrm{j}} \mathrm{x}_{\mathrm{ij}}+\mathrm{ei}$

Keterangan:

Qf $=$ Log Q frontier

bo $=$ Konstanta

$\mathrm{bj}=$ Elastisitas produksi untuk produksi ke-i

xij = Jumlah penggunaan input ke-j untuk usahatani ke-i

ei $=$ Kesalahan (error)

$\mathrm{i}=$ produksi ke- $1,2,3, \ldots$ dan $\mathrm{j}=$ faktor produksi $1,2,3, \ldots$.

Efisiensi teknis usahatani dihitung dengan rumus (Soekartawi 2002), yaitu:

$\mathrm{ET}=\frac{\mathrm{Qi}}{\mathrm{Qf}} \times 100 \%$

Keterangan:

ET $=$ Efisiensi Teknis

Qi $=$ Produksi aktual ke-i

Qf $=$ Produksi potensial/frontier

\section{Analisis Faktor-faktor yang Mempengaruhi Efisiensi Teknis Usahatani Kubis}

Analisis faktor-faktor yang mempengaruhi efisiensi teknis usahatani kubis menggunakan regresi linear berganda. Persamaan yang digunakan yaitu:

$$
Y=a o+a_{1} Z_{1}+a_{2} Z_{2}+a_{3} Z_{3}+a_{4} Z_{4}+a_{5} \ldots \ldots \ldots
$$

Keterangan:

$$
\begin{aligned}
\mathrm{Y}= & \text { Efisiensi teknis usahatani kubis } \\
\mathrm{Ai} & =\text { Koefisien regresi } \\
\mathrm{Z1}= & \text { Luas lahan kubis (ha) } \\
\mathrm{Z} 2= & \text { Biaya usahatani }(\mathrm{Rp}) \\
\mathrm{Z3}= & \text { Tingkat pendidikan petani (tahun) } \\
\mathrm{Z} 4= & \text { Pengalaman usahatani kubis (tahun }) \\
\mathrm{D} 1= & \text { Risiko produksi }(1=\text { risiko tinggi dan } 0= \\
& \text { risiko rendah) } \\
\mathrm{D} 2= & \text { Kredit atau pinjaman }(1=\text { meminjam dan } 0 \\
& =\text { tidak meminjam) } \\
\mathrm{D} 3= & \text { Keikutsertaan kelompok tani }(1=\text { ikut dan } 0 \\
= & \text { tidak ikut) }
\end{aligned}
$$

Setelah itu, dilakukan uji F, untuk mengetahui apakah variabel bebas mempengaruhi variabel terikat secara serentak. Uji t digunakan untuk mengetahui pengaruh masing-masing variabel bebas secara tunggal terhadap variabel terikat. Persamaan dengan model regresi linear diuji ada tidaknya pelanggaran asumsi klasik agar kondisi model tersebut BLUE (Best Linear Unbiased Estimate). Pengujian ini dikenal dengan uji asumsi klasik berupa uji multikolinearitas dan uji heteroskedastis.

\section{HASIL DAN PEMBAHASAN}

\section{Karakteristik Responden}

Umur responden berkisar antara 23-60 tahun. Ratarata umur petani lahan sawah adalah 43 tahun dan petani lahan tegalan adalah 38 tahun. Semua petani lahan sawah maupun tegalan berada pada usia produktif $(100 \%)$. Tingkat pendidikan terbanyak adalah tamatan SD sebesar $40 \%$ untuk petani lahan sawah dan $45,16 \%$ untuk petani lahan tegalan. Petani lahan sawah dan tegalan menanggung anggota keluarga sebanyak 2-3 orang yaitu sebesar $66,67 \%$ dan $77,42 \%$.

Rata-rata pengalaman beusahatani kubis petani lahan sawah adalah 19 tahun dan untuk petani lahan tegalan adalah 16 tahun. Petani lahan sawah dan tegalan memiliki pengalaman berusahatani kubis selama 5-12 tahun yaitu sebesar $50 \%$ dan $61,29 \%$. Petani kubis lahan sawah maupun tegalan banyak yang tidak memiliki pekerjaan sampingan sebesar $63,33 \%$ dan $67,74 \%$. Rata-rata luas lahan sawah yang diusahakan adalah 0,275 hektare, sedangkan lahan tegalan adalah 0,270 hektare. Petani lahan sawah dan tegalan memiliki 
luas lahan antara 0,040-0,320 ha yaitu sebesar 80\% dan $90,32 \%$. Petani lahan sawah dan tegalan memiliki status kepemilikian lahan milik sendiri yaitu sebesar $83,33 \%$ dan 95,33\%. Petani lahan sawah dan tegalanyang tergabung dalam kelompok tani yaitu sebesar $86,67 \%$ dan $80,65 \%$. Sumber modal petani lahan sawah dan tegalan berasal dari modal sendiri yaitu 50\%dan 58,06\%, namun ada sebagian petani yang meminjam pinjaman (kredit) dari tengkulak ataupun pedagang kios pertanian. Risiko produksi yang dihadapi petani dalam usahatani kubis di lokasi penelitian paling banyak disebabkan oleh serangan hama dan penyakit tanaman, sebesar $33,33 \%$ petani lahan sawah dan $38,70 \%$ petani lahan tegalan menghadapi risiko produksi yang tinggi.

\section{Penggunaan Sarana Produksi dan Produksi}

Penggunaan sarana produksi sangat menentukan kuantitas maupun kualitas produksi yang dihasilkan, sehingga penggunaan sarana produksi merupakan faktor penting dalam keberhasilan usahatani kubis. Penggunaan sarana produksi usahatani kubis di Kecamatan Sumberejo Kabupetan Tanggamus dapat dilihat pada Tabel 1.Berdasarkan hasil penelitian, penggunaan benih, pupuk organik maupun kimia oleh petani hanya berdasarkan pengalaman saja, tidak ada ukuran tertentu mengenai dosis penggunaan. Tidak adanya penyuluhan mengenai usahatani kubis mengakibatkan petani tidak mengetahui dosis yang sesuai untuk pemupukan kubis, sedangkan dosis pestisida yang digunakan petani disesuaikan dengan anjuran yang tertera pada label kemasan. Produksi yang dihasilkan oleh petani kubis di lahan sawah sebesar 12.024,24 kg/ha lebih tinggi dibandingkan produksi kubis lahan tegalan sebesar 9.677,42 kg/ha. Perbedaan produksi ini dikarenakan kebutuhan air untuk komoditas kubis di lahan sawah terpenuhi. Petani lahan sawah melakukan pengairan menggunakan irigasi, sedangkan petani lahan tegalan hanya memanfaatkan air hujan saja.

\section{Pendapatan Usahatani Kubis}

Pendapatan petani dipengaruhi oleh penerimaan dan biaya. Analisis pendapatan usahatani kubis disajikan pada Tabel 2.Biaya produksi terbesar berasal dari biaya pupuk phonska dan NPK. Petani kubis banyak menggunakan pupuk phonska karena menurut petani berpengaruh pada pertumbuhan kubis, penggunaan pupuk NPK basf sebagai pengganti pupuk subsidi .
Tabel 1. Penggunaan sarana produksi usahatani kubis per hektare di Kecamatan Sumberejo Kabupaten Tanggamus tahun 2019

\begin{tabular}{|c|c|c|c|}
\hline \multirow{2}{*}{ Sarana Produksi } & Sawah & Tegalan & \multirow{2}{*}{$\begin{array}{c}\text { Anjuran } \\
\text { Per hektar }\end{array}$} \\
\hline & Jumlah & Jumlah & \\
\hline Benih Grand 22 (g) & 134,55 & 161,29 & 200,00 \\
\hline Kandang (kg) & $1.412,12$ & $3.058,54$ & $30.000,00$ \\
\hline Urea $(\mathrm{kg})$ & 200,00 & 83,63 & 100,00 \\
\hline $\mathrm{ZA}(\mathrm{kg})$ & 154,55 & 155,32 & 250,00 \\
\hline TSP (kg) & 153,94 & 203,11 & 250,00 \\
\hline Phonska (kg) & 275,76 & 256,87 & - \\
\hline NPK Basf (kg) & 73,58 & 117,68 & - \\
\hline \multicolumn{4}{|l|}{ Insektisida } \\
\hline Siklon (g) & 69,70 & 29,87 & - \\
\hline Fastac (ml) & 48,48 & 71,68 & - \\
\hline Biocron (ml) & 109,09 & 59,74 & - \\
\hline Virtako (ml) & 96,97 & 47,79 & - \\
\hline Curacon (ml) & 169,70 & 155,32 & - \\
\hline Regent (ml) & 303,03 & 537,63 & - \\
\hline Prevathon (ml) & 72,73 & 11,95 & - \\
\hline Dursban (ml) & 36,36 & 23,89 & - \\
\hline \multicolumn{4}{|l|}{ Fungisida } \\
\hline Antracol (kg) & 1,09 & 0,90 & - \\
\hline Dupont (ml) & 36,36 & 119,47 & - \\
\hline Amistar Top (ml) & 24,24 & 11,95 & - \\
\hline Dithane $(\mathrm{g})$ & 72,73 & 143,37 & - \\
\hline
\end{tabular}

Pupuk NPK basf merupakan pupuk impor yang harganya tinggi, sehingga biaya yang dikeluarkan petani juga tinggi. Penerimaan usahatani kubis lahan sawah lebih besar dibandingkan dengan usahatani kubis lahan tegalan, karena produksi kubis di lahan sawah lebih besar, sehingga pendapatan usahatani kubis lahan sawah juga lebih besar daripada lahan tegalan.

Pendapatan atas biaya tunai usahatani kubis lahan sawah adalah Rp26.597.721,71/ha/MT, sedangkan pendapatan atas biaya total usahatani kubis lahan tegalan adalah Rp21.306.672,51/ha/MT. Hasil uji beda pendapatan atas biaya tunai menunjukkan nilai t hitung sebesar 1,819 (signifikansi $<0,1$ ), maka terdapat perbedaan antara pendapatan atas biaya tunai usahatani kubis lahan sawah dan lahan tegalan. Hasil uji beda pendapatan atas biaya total menunjukkan nilai $\mathrm{t}$ hitung sebesar 1,788 (signifikansi $<0,1$ ), makaterdapat perbedaan antara pendapatan atas biaya total usahatani kubis pada lahan sawah dengan lahan tegalan.

Nisbah penerimaan terhadap biaya tunai dan biaya total $(\mathrm{R} / \mathrm{C})$ usahatani kubis lahan sawah lebih besar dibandingkan dengan lahan tegalan, namun nilai $\mathrm{R} / \mathrm{C}$ keduanya lebih dari satu. Nisbah penerimaan terhadap biaya tunai usahatani kubis biaya tunai yang dikeluarkan oleh petani pada 
Tabel 2. Analisis pendapatan usahatani kubis di Kecamatan Sumberejo Kabupaten Tanggamus tahun 2019

\begin{tabular}{|c|c|c|c|c|c|c|c|}
\hline \multirow{3}{*}{ Uraian } & \multicolumn{4}{|c|}{ Lahan sawah } & \multicolumn{3}{|c|}{ Lahan tegalan } \\
\hline & \multirow[t]{2}{*}{ Satuan } & \multirow{2}{*}{$\begin{array}{c}\text { Harga } \\
\text { (Rp/s at) }\end{array}$} & \multicolumn{2}{|c|}{ Per hektar } & \multirow{2}{*}{$\begin{array}{c}\text { Harga } \\
\text { (Rp/s at) }\end{array}$} & \multicolumn{2}{|c|}{ Per hektar } \\
\hline & & & Jumlah & Nilai (Rp) & & Jumlah & Nilai (Rp) \\
\hline 1 Penerimaan & & & \multicolumn{2}{|r|}{$32.625 .777,78$} & \multicolumn{3}{|c|}{$31.155 .046,83$} \\
\hline Produksi kubis & $\mathrm{kg}$ & $2.713,33$ & $12.024,24$ & $32.625 .777,78$ & $3.219,35$ & $9.677,42$ & $31.155 .046,83$ \\
\hline \multicolumn{8}{|l|}{2 Biaya Produksi } \\
\hline Biaya Tunai & & & & $6.028 .056,06$ & & & $6.345 .866,45$ \\
\hline Benih Grand 22 & $\mathrm{~g}$ & $4.221,87$ & 134,55 & $568.032,97$ & $4.242,71$ & 161,29 & $684.308,01$ \\
\hline Pupuk Kandang & $\mathrm{kg}$ & 273,75 & $1.412,12$ & $386.568,18$ & 241,48 & $3.058,54$ & $738.581,35$ \\
\hline Pupuk Urea & $\mathrm{kg}$ & $2.128,57$ & 200,00 & $425.714,29$ & $2.300,00$ & 83,63 & $192.353,64$ \\
\hline Pupuk ZA & $\mathrm{kg}$ & $2.166,67$ & 154,55 & $334.848,48$ & $2.400,00$ & 155,32 & $372.759,86$ \\
\hline Pupuk TSP & $\mathrm{kg}$ & $2.675,00$ & 153,94 & $411.787,88$ & $2.900,00$ & 203,11 & $589.008,36$ \\
\hline Pupuk Phonska & $\mathrm{kg}$ & $2.781,82$ & 275,76 & $767.107,44$ & $2.800,00$ & 256,87 & $719.235,36$ \\
\hline Pupuk NPK Bass & $\mathrm{kg}$ & $9.671,43$ & 73,58 & $711.582,68$ & $7.136,36$ & 117,68 & $839.822,96$ \\
\hline Insektisida & & & & $499.696,97$ & & & $316.487,46$ \\
\hline Fungisida & & & & $214.515,15$ & & & $252.389,49$ \\
\hline TK Luar Keluarga & $\mathrm{HOK}$ & $50.000,00$ & 33,83 & $1.691 .515,15$ & $50.000,00$ & 30,05 & $1.502 .389,49$ \\
\hline Pajak Lahan & $\mathrm{Rp}$ & & & $16.686,87$ & & & $20.011,95$ \\
\hline Sewa Lahan & $\mathrm{Rp}$ & $2.000 .000,00$ & 0,00 & 0,00 & $2.000 .000,00$ & 0,06 & $118.518,52$ \\
\hline Biaya diperhitungkan & & & & $5.291 .049,21$ & & & $5.086 .607,47$ \\
\hline Penyusutan Alat & $\mathrm{Rp}$ & & & $273.473,45$ & & & $102.378,08$ \\
\hline TK Dalam Keluarga & HOK & $50.000,00$ & 60,35 & $3.017 .575,76$ & $50.000,00$ & 62,05 & $3.102 .747,91$ \\
\hline Sewa Lahan (milik) & $\mathrm{Rp}$ & $2.000 .000,00$ & 1,00 & $2.000 .000,00$ & $2.000 .000,00$ & 0,94 & $1.881 .481,48$ \\
\hline Biaya Total & & & & $11.319 .105,27$ & & & $11.432 .473,92$ \\
\hline \multicolumn{8}{|l|}{3 Pendapatan } \\
\hline Atas Biaya Tunai & & & & 26.597.721,71 & & & $24.809 .180,38$ \\
\hline Atas Biaya Total & & & & $21.306 .672,51$ & & & 19.722.572,91 \\
\hline \multicolumn{8}{|l|}{4 R/C Rasio } \\
\hline Atas Biaya Tunai & & & & 5,41 & & & 4,91 \\
\hline Atas Biaya Total & & & & 2,88 & & & 2,73 \\
\hline
\end{tabular}

lahan sawah adalah 5,41, berarti setiap Rp1,00 akan menghasilkan penerimaan sebesar Rp5,41. Nilai $\mathrm{R} / \mathrm{C}>1$ menunjukkan bahwa penerimaan yang diterima petani lebih besar dibandingkan dengan biaya produksi yang dikeluarkan. Dengan demikian, usahatani kubis di Kecamatan Sumberejo Kabupaten Tanggamus menguntungkan dan layak untuk di lanjutkan. Hasil penelitian ini sejalan dengan hasil penelitian Masitoh, Nahraeni, dan Prahari (2013), Aini, Prasmatiwi, dan Sayekti (2015), dan Nurmala, Soetoro, dan Noormansyah (2016), yaitu usahatani kubis menguntungkan.

\section{Efisiensi Teknis Usahatani Kubis}

Tingkat efisiensi teknis diperoleh dengan cara membandingkan produksi aktual yang dihasilkan oleh petani kubis dengan produksi potensialnya (frontier). Hasil pendugaan koefisien regresi fungsi produksi frontier usahatani kubis diperoleh dengan mencari rata-rata penggunaan sarana produksi usahatani kubis. Hasil pendugaan koefisien regresi fungsi produksi frontier pada usahatani kubis di lokasi penelitian merupakan hasil olah data dari software lindo. Hasil penduga koefisien regresi dapat dilihat pada Tabel 3.

Variabel yang berpengaruh dan memiliki nilai koefisien yang tinggi adalah benih dan luas lahan. Penggunaan benih pada lahan sawah lebih rendah dibandingkan dengan lahan tegalan, sehingga penambahan satu persen benih pada lahan sawah akan meningkat efisiensi teknis sebesar 1,6560 persen. Selain itu, variabel luas lahan sesuai dengan kondisi di lokasi penelitian, dimana ratarata luaslahan tegalan yang diusahakan hanya sebesar 0,270 ha, sehingga perlu penambahanluas lahan agar produksi kubis dapat ditingkatkan dengan maksimum. Namun kondisi tersebut sulit diterapkan karena keterbatasan kepemilikan lahan, sehingga petani dapat meningkatkan sarana produksi yang lain yang dapat meningkatkan produksi. Peningkatan sarana produksi tentunya akan berpegaruh terhadap tingkat efisiensi teknis usahatani kubis. 
Tabel 3. Hasil penduga koefisien regresi fungsi produksi frontier usahatani kubis di Kecamatan Sumberejo Kabupaten Tanggamus tahun 2019

\begin{tabular}{lcc}
\hline \multirow{2}{*}{ Variabel } & \multicolumn{2}{c}{ Koefisien } \\
\cline { 2 - 3 } & Lahan sawah & Lahan Tegalan \\
\hline Konstanta & 0,9824 & 2,6896 \\
Log X1 (Benih) & 1,6560 & 0,9871 \\
Log X2 (Luas lahan) & 0,0912 & 1,1648 \\
Log X3 (Pupuk Kandang) & 0,0000 & 0,0489 \\
Log X4 (Pupuk Urea) & 0,0151 & 0,0000 \\
Log X5 (Pupuk ZA) & 0,0052 & 0,0238 \\
Log X6 (Pupuk TSP) & 0,0000 & 0,0140 \\
Log X7 (Pupuk Phonska) & 0,0020 & 0,0000 \\
Log X8 (Pupuk NPK Bass) & 0,0022 & 0,0060 \\
Log X9 (Tenaga Kerja) & 0,1343 & 0,0000 \\
\hline
\end{tabular}

Usahatani kubis dikatakan efisien secara teknis apabila produksi aktual yang dihasilkan sama atau mendekati dari produksi frontier.Tingkat efisiensi teknis usahatni kubis lahan sawah dan tegalan di Kecamatan Sumberejo Kabupaten Tanggamus dapat dilihat pada Tabel 4.

Rata-rata tingkat efisiensi teknis usahatani kubis lahan sawah (71\%) lebih besar dibandingkan lahan tegalan (61,01\%). Perbedaan ini dikarenakan usahatani kubis lahan sawah melakukan pengairan, sehingga kebutuhan air untuk kubis terpenuhi, sedangkan usahatani kubis lahan tegalan hanya memanfaatkan air hujan. Oleh karena itu, produksi aktual kubis lahan sawah lebih tinggi daripada lahan tegalan. Dengan demikian, akan berdampak pada tingkat efisiensi teknis usahatani kubis.

Klasifikasi yang digunakan adalah sangat efisien jika nilai $\geq 0,9$, cukup efisien jika nilai $0,7-0,8$, dan belum efisien jika nilai $<0,7$ (Coelli dan Battese 1998). Klasifikasi tingkat efisiensi teknis usahatani kubis dapat dilihat pada Tabel 5 . Sebagian besar usahatani kubis lahan sawah (50\%) dan tegalan $(58,06 \%)$ belum efisien secara teknis, namun ada delapan petani lahan sawah dan tujuh petani lahan tegalan yang usahataninya

Tabel 4. Efisiensi teknis usahatani kubis di Kecamatan Sumberejo Kabupaten Tanggamus tahun 2019

\begin{tabular}{lrr}
\hline \multirow{2}{*}{ Keterangan } & \multicolumn{2}{c}{ Lahan } \\
\cline { 2 - 3 } & \multicolumn{1}{c}{ Sawah } & \multicolumn{1}{c}{ Tegalan } \\
\hline Produksi Aktual (Qi) & $3.306,67$ & $2.612,90$ \\
Produksi Frontier (Qf) & $5.255,17$ & $5.084,19$ \\
Efisiensi Teknis (ET) & 71,00 & 61,01 \\
\hline
\end{tabular}

Tabel 5. Tingkat efisiensi teknis usahatani kubis di Kecamatan Sumberejo Kabupaten Tanggamus tahun 2019

\begin{tabular}{|c|c|c|c|c|}
\hline \multirow[b]{2}{*}{ Klasifikasi } & \multicolumn{2}{|c|}{ Lahan sawah } & \multicolumn{2}{|c|}{ Lahan tegalan } \\
\hline & $\begin{array}{l}\text { Jumlah } \\
\text { (orang) }\end{array}$ & $(\%)$ & $\begin{array}{l}\text { Jumlah } \\
\text { (orang) }\end{array}$ & $(\%)$ \\
\hline$<0,7$ & 15 & 50,00 & 18 & 58,06 \\
\hline $0,7-0,8$ & 4 & 13,33 & 5 & 16,13 \\
\hline$\geq 0,9$ & 11 & 36,67 & 8 & 25,81 \\
\hline Jumlah & 30 & 100,00 & 31 & 100,00 \\
\hline
\end{tabular}

sudah efisien secara teknis.Hasil uji one sample $t$ test menunjukkan nilai t-hitung untuk lahan sawah adalah $-6,485$ dengan taraf kepercayaan 99 persen, maka usahatani kubis pada lahan sawah belum efisien secara teknis. Nilai t- hitung untuk lahan tegalan adalah -7,607 dengan taraf kepercayaan 99 persen, maka usahatani kubis pada lahan tegalan juga belum efisien secara teknis.

Hasil penelitian ini sejalan dengan penelitian Wibisono (2011), Darmansyah, Sukiyono, dan Sugiarti (2013), dan Hidayati (2018), dimana usahatani kubis belum efisien secara teknis.Hasil uji independent sample test menunjukkan nilai $\mathrm{t}$ hitung sebesar 1,461 (signifikansi $>0,1$ ), berarti bahwa tidak terdapat perbedaan antara efisiensi teknis usahatani kubis pada lahan sawah dengan lahan tegalan.

\section{Faktor - faktor yang Mempengaruhi Efisiensi Teknis Usahatani Kubis}

Faktor-faktor yang mempengaruhi efisiensi teknis usahatani kubis dianalisis menggunakan regresi linier berganda. Sebelum data diolah, dilakukan uji asumsi klasik berupa uji multikolinieritas dan heterokedastisitas terlebih dahulu. Model lahan sawah dan tegalan tidak mengalami masalah multikolinieritas dan heterokedastisitas. Hasil regresi dapat dilihat pada Tabel 6 .

Variabel luas lahan kubis tidak berpengaruh terhadap tingkat efisiensi teknis usahatani kubis lahan sawah, namun berpengaruh negatif terhadap tingkat efisiensi teknis usahatani kubis lahan tegalan, yang berarti setiap penambahan luas lahan akan menurunkan tingkat efisiensi teknis usahatani kubis. Petani lahan tegalan tidak melakukan pengairan, hanya memanfaatkan air hujan sebagai pengairan, sehingga produksi yang dihasilkan lebih rendah dibandingkan produksi lahan sawahdan berdampak pada penurunan tingkat efisiensi teknis. 
Tabel 6. Faktor-faktor yang mempengaruhi efisiensi teknis usahatani kubis di Kecamatan Sumberejo Kabupaten Tanggamus tahun 2019

\begin{tabular}{|c|c|c|c|c|c|c|c|c|}
\hline \multirow{2}{*}{ Variabel } & \multicolumn{4}{|c|}{ Lahan sawah } & \multicolumn{4}{|c|}{ Lahan tegalan } \\
\hline & Koef. Re & & t-hitung & Sig & Koef. Re & resi & t-hitung & Sig \\
\hline Konstanta & 0,209 & & 1,552 & 0,135 & $-0,191$ & & $-1,511$ & 0,144 \\
\hline Z1 (Luas lahan kubis) & 0,376 & & 1,385 & 0,180 & $-0,520$ & ** & $-2,163$ & 0,041 \\
\hline Z2 (Biaya usahatani) & $-0,024$ & $* *$ & $-2,13$ & 0,045 & 0,013 & * & 1,896 & 0,071 \\
\hline Z3 (Pendidikan) & 0,055 & $* * *$ & 3,321 & 0,003 & 0,072 & $* * *$ & 5,694 & 0,000 \\
\hline Z4 (Pengalaman) & 0,015 & $* *$ & 2,586 & 0,017 & 0,017 & $* * *$ & 2,953 & 0,007 \\
\hline D1 (Risiko produksi) & $-0,021$ & & $-0,397$ & 0,695 & 0,014 & & 0,406 & 0,688 \\
\hline D2 (Kredit) & $-0,032$ & & $-0,665$ & 0,513 & 0,050 & & 1,225 & 0,233 \\
\hline D3 (Kelompok Tani) & $-0,006$ & & $-0,087$ & 0,931 & $-0,050$ & & $-1,04$ & 0,309 \\
\hline $\mathrm{R}^{2}$ & 0,828 & & & & 0,927 & & & \\
\hline $\mathrm{R}^{2}$ adjusted & 0,774 & & & & 0,904 & & & \\
\hline F-hitung & 15,177 & & & 0,000 & 41,418 & & & 0,000 \\
\hline
\end{tabular}

Keterangan :

$* * *)=$ nyata pada taraf kepercayaan $99 \%$

$* *$ ) = nyata pada taraf kepercayaan $95 \%$

*) = nyata pada taraf kepercayaan $90 \%$

Biaya usahatani berpengaruh terhadap efisiensi teknis usahatani kubis lahan sawah dan tegalan, namun nilai koefisien untuk lahan sawah bernilai negatif, yang berarti peningkatan biaya akan menurunkan tingkat efisiensi teknis usahatani kubis lahan sawah, karena biaya total yang dikeluarkan petani lahan sawah lebih besar dibandingkan petani lahan tegalan. Harga pupuk non subsidi yang diterima petani lahan sawah lebih tinggi, sehingga biaya yang dikeluarkan lebih besar dan jumlah pupuk yang digunakan juga belum sesuai dengan anjuran.

Pendidikan berpengaruh positif terhadap efisiensi teknis usahatani kubis lahan sawah dan tegalan di Kecamatan Sumberejo Kabupaten Tanggamus. Semakin tinggi tingkat pendidikan akan mempengaruhi cara berpikir petani. Petani akan mengusahakan menggunakan sarana produksi yang sesuai anjuran agar produksi yang dihasilkan maksimum. Apabila produksi yang dihasilkan meningkat, maka akan berdampak pada peningkatan pendapatan petani.

Pengalaman usahatani kubis berpengaruh positif terhadap tingkat efisiensi teknis usahatani kubis lahan sawah dan tegalan di Kecamatan Sumberejo Kabupaten Tanggamus. dikarenakan petani yang sudah berpengalaman diharapkan mampu mengelola usahataninya.Petani yang berpengalaman memiliki kapabilitas manajerial yang baik untuk digunakan dalam mengambil keputusan yang rasional.Hasil penelitian ini sejalan . [28 0ktober 2018] dengan Hidayati (2018), dimana pengalaman usahatani berpengaruh terhadap tingkat efisiensi teknis.

\section{KESIMPULAN}

Pendapatan usahatani kubis lahan sawah dan tegalan di Kecamatan Sumberejo Kabupaten Tanggamus berbeda, namun keduanya menguntungkan. Tingkat efisiensi teknis usahatani kubis lahan sawah dan tegalan tidak berbeda dan keduanya belum efisien secara teknis.Faktor yang berpengaruh terhadap efisiensi teknis usahatani kubis lahan sawah dan tegalan. adalah biaya usahatani, faktor-faktor yang berpengaruh positif adalah pendidikan petani dan pengalaman usahatani kubis, sedangkan faktor yang hanya berpengaruh negatif terhadap efisiensi teknis usahatani kubis lahan tegalan adalah luas lahan kubis. Peningkatan penggunaan sarana produksi yang sesuai anjuran akan meningkatan tingkat efisiensi teknis usahatani yang berdampak pada peningkatan pendapatan usahatani kubis.

\section{DAFTAR PUSTAKA}

Aini NH, Prasmatiwi FE, dan Sayekti WD. 2015. Analisis pendapatan dan risiko usahatani kubis pada lahan kering dan lahan sawah tadah hujan di Kecamatan Gisting Kabupaten Tanggamus. JIIA, 3 (1): 1-9. http://jurnal.fp.unila.ac.id/index.php/JIA/art icle/view/1011 
BPPP [Badan Pengkajian dan Pengembanan Perdagangan].2017. Peluang Ekspor Produk Hortikultura. Warta Pengkajian Perdagangan, 1 (13): 1 40.http://bppp.kemendag.go.id/warta_peng kajian/view/MTg\%3D. [24 Oktober 2018]

BPS [Badan Pusat Statistik] Kabupaten Tanggamus. 2018. Kabupaten Tanggamus dalam Angka 2018. BPS Kabupaten Tanggamus. Kabupaten Tanggamus.https://tanggamuskab.bps.go.id/publication.html?Publikasi\%5Btahun Judul \%5D=2018\&Publikasi\%5BkataKunci $\% 5 \mathrm{D}=$ kabupaten+tanggamus + dalam + angka $+2018 \& y t 0=$ Tampilkan. [22 Oktober 2018]

BPS [Badan Pusat Statistik] Provinsi Lampung. 2018. Lampung dalam Angka 2018. BPS Provinsi Lampung. Bandar Lampung. https://lampung.bps.go.id/publication/2018/ 08/16/8a37f460958edf158a0314de/provinsi -lampung-dalam-angka-2018.html. [22 Oktober 2018]

BPS [Badan Pusat Statistik]. 2016. Statistik Tanaman Sayuran dan Buah-buahan Semusim Indonesia. BPS. Jakarta. https://www.bps.go.id/publication/2017/10/ 02/9d10a13049cee1ce8aad9768/statistiktanaman-sayuran-dan-buah-buahansemusim-indonesia-2016.html. [22 Oktober 2018] 2018. Pertumbuhan Ekonomi Indonesia Triwulan II-2018. BPS. Jakarta.

https://www.bps.go.id/pressrelease/2018/08 /06/1521/ekonomi-indonesia-triwulan-ii-

2018-tumbuh-5-27-persen.html.

Oktober 2018]

BP3K [Balai Penyuluhan Pertanian, Perikanan, dan Kehutanan Kecamatan Sumberejo]. 2016. Progama Penyuluhan Kecamatan Sumberejo tahun 2016. BP3K Kecamatan Sumberejo. Kabupaten Tanggamus.

Coelli TJ and Battese GE. 1998. An Introduction to Efficiency and Productivity Analysis. Kluwer Academic Publisher. Boston. https://books.google.co.id/books?id=NMYB $0 \mathrm{Mh} 81 \mathrm{jcC} \&$ printsec $=$ frontcover $\& \mathrm{dq}=\mathrm{An}+\mathrm{Int}$ roduction+to+Efficiency+and+Productivity+ Analysis\&hl $=\mathrm{id} \& \mathrm{sa}=\mathrm{X} \& \mathrm{ved}=0 \mathrm{ahUKEwi8m}$ qTNobzjAhXa8HMBHcXmBSAQ6AEILD $\mathrm{AA} \# \mathrm{v}=$ onepage $\& \mathrm{q}=\mathrm{An} \% 20$ Introduction $\% 2$ 0to $\% 20$ Efficiency $\% 20$ and $\% 20$ Productivity \%20Analysis\&f=false. [27 April 2019]

Darmansyah AN, Sukiyono K, dan Sugiarti S. 2013. Analisis efisiensi teknis dan faktor yang mempengaruhi efisiensi pada usaha tani kubis di Desa Talang Belitar Kecamatan Sindang Dataran Kabupaten Rejang Lebong. Agrisep, 12 (20): 177194.https://ejournal.unib.ac.id/index.php/ag risep/article/view/482. [28 0ktober 2018]

Hidayati, R. 2018. Analisis efisiensi teknis usahatani kubis di Kabupaten Agam, Sumatera Barat. Jurnal Hexagro, 2 (1): 2229.https://www.e-journal.unper.ac.id/index.php/hexagro/article/view/114. [28 Oktober 2018]

Isaac S, dan Michael WB. 1981. Handbook in Research and Evaluation. Edits Publishers. California.https://books.google.co.id/books?id=05RgQgAACAAJ\&dq=Handbo $\mathrm{ok}+\mathrm{in}+$ Research + and + Evaluation $\& \mathrm{hl}=\mathrm{id} \& \mathrm{~s}$ $\mathrm{a}=$ X\&ved=0ahUKEwjm9Jq0o7zjAhX47X MBHdh6BToQ6AEIKTAA. [10 November 2018]

Masitoh S, Nahraeni W, dan Prahari B. 2013. Analisis efisiensi penggunaan faktor-faktor produksi usaha tani kubis (Brassica oleracea) di Kertasari, Bandung, Jawa Barat. Jurnal Pertanian ISSN 2087-4936, 4 (2): $\quad$ 101-108.http://ojs.unida.ac.id/index.php/jp/article/view/61. [28 0ktober 2018]

Nurmala L, Soetoro, dan Noormansyah Z. 2016. Analisis biaya, pendapatan dan R/C usahatani kubis (Brassica oleraceal) (suatu kasus di Desa Cibeureum Kecamatan Sukamantri Kabupaten Ciamis). Jurnal Ilmiah Mahasiswa AGROINFO GALUH, 2 (2): 97-102. https://jurnal.unigal.ac.id/index.php/agroinfogaluh/article/download/ 64/62. [28 0ktober 2018]

Soekartawi. 2002. Analisis Usahatani. UI Press. Jakarta.

Wibisono H. 2011. Analisis efisiensi usahatani kubis (studi empiris di Desa Banyuroto Kecamatan Sawangan Kabupaten Magelang). Jurnal Surya Agritama, 2(1) : 1-10.http://ejournal.umpwr.ac.id/index.php/surya-agritama/article/view/336. [28 Oktober 2018] 